$\begin{array}{llll}\text { AL-Qadisiya Journal of Vet.Med.Sci. } \quad \text { Vol./12 } & \text { No./1 }\end{array}$

\title{
Partial Hepatectomy Achievement by New Device in Rabbits Model
}

\author{
W. A. Alheani \\ E. R. Al-Kennany \\ Coll. of Vet. Med./Univer. of Anbar \\ Coll. of Vet. Med./ Unive. of Mosul.
}

\begin{abstract}
This study was to evaluate the efficiency of new device (heat gun) for liver surgery. This instrument is firstly introduce to the surgery to control bleeding during tissue dissection.Eighteen rabbits aged between 3-4 months weighted between 1.5- $2 \mathrm{~kg}$ from both sex were used in this experiment. The rabbits were divided into three groups. First group (A) underwent partial hepatectomy by heat gun to posterior left lobe of liver and second group (B) underwent partial hepatectomy by using suturing of severed posterior left lobe of liver served as positive control . The third group (C) underwent laprotomy only and served as negative control.Postoperative examination of physiological parameters was measured for 3 postoperative days, The animal were scarified after $7,15,21$ days after operation for gross and histopathological examination.The results revealed that efficiency of heat gun for partial hepatectomy and it was a fast method and prevented bleeding from the incision site and it is decreased time that needed for suturing hepatic incision in liver surgery.The physiological parameters in all the experimental rabbits were within normal range during the three days following the operations, and they gained their normal body activities and food intake.In gross pathological examination there is no serious complication that recorded except adhesion with omentum that is considered advantage for sealing incision and preventing adhesion with other neighboring viscera and prevent possible bleeding from hepatic incision. In histopathology the rabbits in group (A) show faster regeneration than in group (B).In conclusion, the heat gun is effective device for partial hepatectomy rabbits models and It is the first use for this purpose in this animals.
\end{abstract}

Key words :Partial Hepatectomy ,Heat gun, suture, Histopathology, Gross pathology ,Rabbits.

\section{Introduction}

The rabbit is a widely distributed animal and it is used as model for numerous medical experiments (1). Surgery of the liver is complicated by the fact that hepatic tissue is friable (2) and reducing blood loss during surgery is the major objective of the surgeon because blood loss is associated with an increased post operative complication rate a decreased long-term survival rate in patients undergoing partial liver resection $(3,4,5)$. Most of the blood loss occurs during the transection phase therefore in the last decades transection techniques have been refined. Clamp crushing, ultrasonic dissector, hydrojet and dissecting sealer are frequently used techniques. However, no technique has been shown to be the optimal and appears particularly dependent on the individual surgeon's preference $(6,7,8,9)$. Our experiment was designed for the following purposes.

1- To standardize the new technique for partial hepatectomy in rabbits as model.

2-Study of the gross and histopathological changes of the liver and adjacent viscera following the surgery.

\section{Materials and Methods}

Eighteen rabbits aged between 3-4 months weighted between $1.5-2 \mathrm{~kg}$ from both sex were used in this experiment. The rabbits were clinically healthy, and kept in the cages at the College of Veterinary Medicine. Food and water were given freely during the adaptation period.
The Heat gun device (Guangzhou XinYue Co.Ltd,China) is consist of:

1. Control panel

2. Conducting tube

3. Head piece 


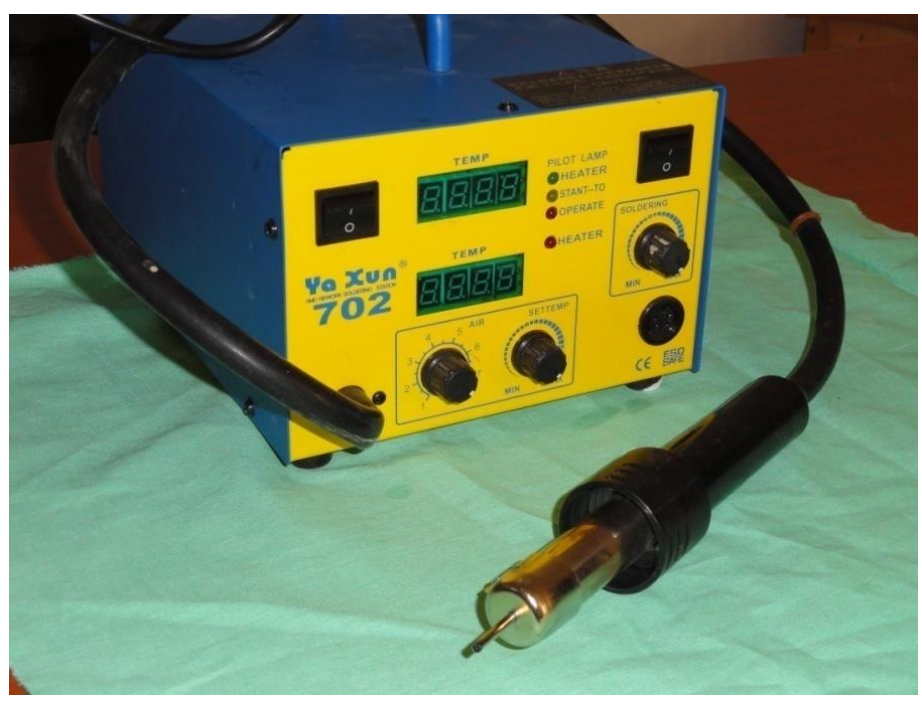

Fig.1 Heat gun apparatus

The experiment design as the followings:

A total number of 18 rabbits were divided randomly into three groups each group have 6 rabbits. The rabbits in group A underwent partial hepatectomy by blunt dissection with scissor after coagulation of tissue that intend to be removed by using hot air and after cutting of tissue we apply of hot air to the cut surface for complete hemostasis. While animals in group B underwent partial hepatectomy with extrtracorporial suturing of the stump using vicryl suture and served as positive control. The third group underwent laprotomy only and served as negative control.The gross pathological changes of the liver of the hepatic incision line were performed at 7, 15 and 21 postoperative days respectively in all groups.

\section{Surgical technique}

The anesthetized rabbit was covered with surgical drapes and fixed by towel clips to the skin. All the experimental rabbits according to the following steps.A lapratomy was performed under general anesthesia by incision from xyphoid to umbilicus and after making incision we explored the abdomen cavity the exposed the liver and determine the site of cutting in the left lobe after bring the lobe to outside the incision we do the following according to group of experiment:

\section{Group A}

A hand piece of the heat gun was placed vertically on the liver surface then application of hot air along the incision line planned for partial hepatectomy to provide coagulation of tissue then cutting the parenchyma by scissor afterword applying the hot air to the cutting surface for complete hemostasis. 


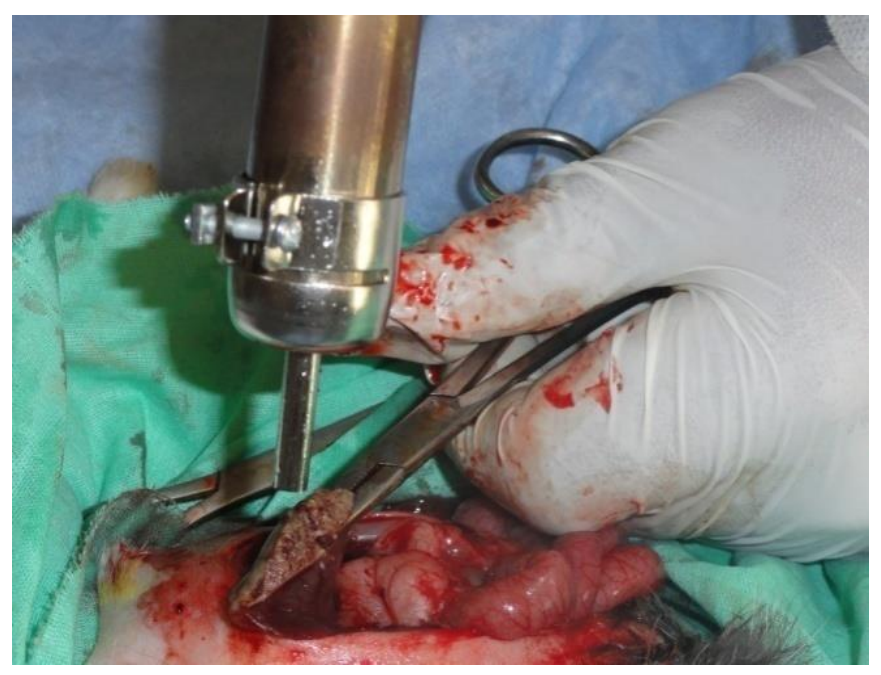

\section{Group B}

The liver parenchyma was fractured by using hemostatic forceps the suturing the cutting surface by using vicryl with continuous pattern. After doing partial hepatectomy, the abdominal muscles and skin close by routine methods.

\section{Group C}

The animals underwent lapartomy and then suturing abdominal muscles and skin by routine methods

\section{Postoperative care}

The experimental rabbis received penicilline - streptomycin (Combi, Kela Labarotoria, Belgium). in a dose of 10.000 I.U/Kg B. W. penicilline and $10 \mathrm{mg} / \mathrm{kg} \mathrm{B}$. W. streptomycin for 3 days by I.M route injection. Milk was given to the rabbits as a liquid food for 3 days postoperatively, then gradually returned to the normal solid food.Physical examination of the rabbits in the first 3 days postoperatively was also done particularly concerning the body temperature and food intake. Skin sutures were removed 10 days after the operation.

\section{Surgical Approach}

The midline incision was best approach for partial liver resection.

\section{Partial hepatectomy by heat gun}

Hepatectomy incision in group A rabbits was closed successfully by the hot air application. The results revealed that it was a fast method and prevent bleeding from the incision site, and without tearing of the 


\section{$\begin{array}{llll}\text { AL-Qadisiya Journal of Vet.Med.Sci. } & \text { Vol./12 } & \text { No./1 }\end{array}$}

wound edges and no bile leakage. The mean time for the operation period in group A was $25 \mathrm{~min} \pm 5 \mathrm{~min}$.

\section{Extracorporeal suturing}

Hepatectomy incision in group B rabbits was closed successfully by extracorporeal suturing in a simple continuous technique using 3/0 Vicryl suture material. The incision was closed perfectly with a best apposition of the wound edges There was no tearing of the wound edges and no bile leakage. The results also indicate that extracorporeal suturing was need much time when compared with clips closing. The mean time for the operation period was 35 min. \pm 5 min. The study revealed that vicryl was a perfect suture material that could be used in the liver surgery. It has good handling properties and a high tensile strength, with high knot security.

\section{Post operative examination.}

There were no clinical signs of postoperative pain appeared on the animals. All the animals in all groups started eating soft food (milk) after 24 hours postoperatively, and after 3 days returned to the normal solid food.No signs of peritonitis or ileus were reported in any of the experimental rabbits, which gained normal body activity, normal food intake and normal defecation within 3 days after the operation.

\section{Gross pathological changes.}

Group A in which the rabbits underwent partial hepatectomy with heat gun of hepatic incision, gross pathological examination showed adhesion of the incision site with omental flap that covered the incision completely in all group A rabbits. While, there was no variation in the degree of adhesion between animals that were examined after 7, 15 and 21 days postoperatively. The incision site was hard in consistency and appeared normal with no signs infection, and no adhesion with other viscera was reported Group B in which the rabbits underwent partial hepatectomy with extracorporeal closure of the incision using vicryl suture, the incision sites were moderate adhesion with the omentum without any adhesion with other abdominal viscera. Parts of the vicryl thread still existed unabsorbed in animals that examined 7 days after the operation while it was less clear in animals that were examined at 15 and 21 postoperative days respectively.

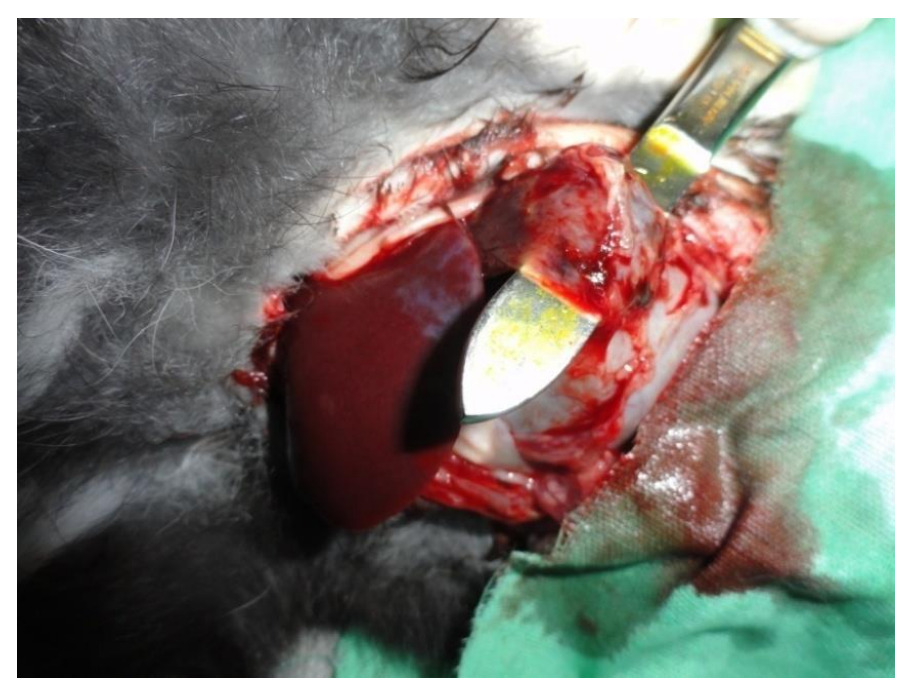

Fig. 3 Adhesion stump with omentum 


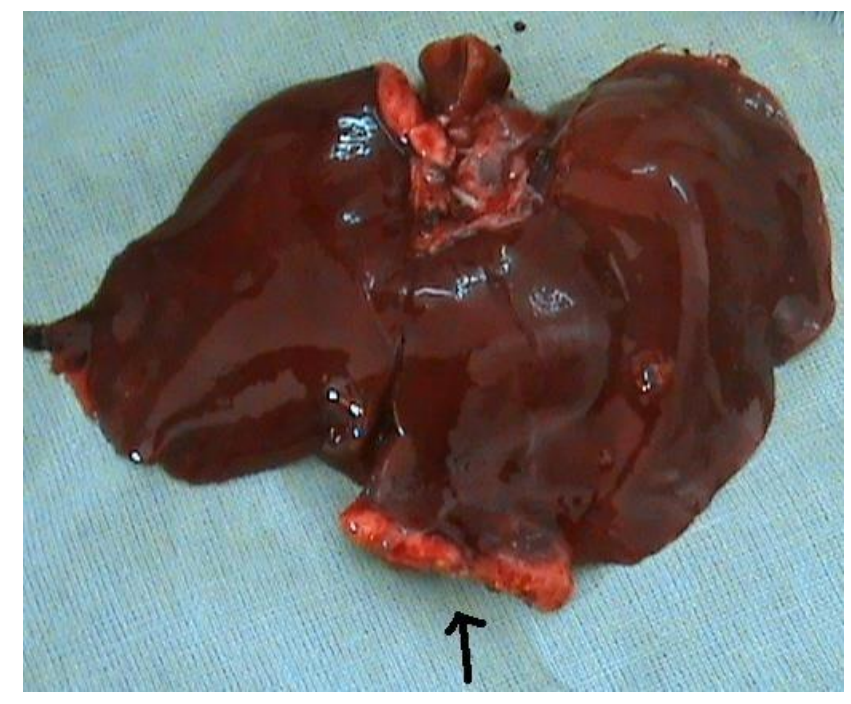

Fig. 4The stump of liver in after removal of liver from abdomen

\section{Histopathology}

Liver section of rabbits in group A revealed histopathological changes at 7 days post operation represent by hypertrophy of hepatocytes with increase in the size of nucleus and hepatocytes become hepatomegali in addition to take different affinity of staining. Severe vacuolar degeneration and severe congestion of blood vessels (central and portal vein and artery) and pigmentation also observed (Figs 5-7). The Kupffer elucidate hypertrophy and hyperplasia as compared with group C. Increase number of binucleated hepatocytes in addition to increase mitotic figures and infiltration of mono nuclear cells. All these lesions continued at 15 days associated with severe fibrosis in portal area, which contain fibroplasia and newly formed portal area. Hypertrophy and hyperplasia in epithelium lining bile duct associated with infiltration of mononuclear inflammatory cells (lymphocyte) (Figs 8-10) .At 21 days post operation, then changes continued with signs of regeneration include fibroplasia and angioplasia in portal area in addition to lobulation and apoptosis of hepatocyte (Figs 11-14). However in group B liver section elucidate the presence of loss normal architectures of hepatic cord and pigmentation of hypertrophied Kupffer's cells, congestion of blood vessels, also hepatocyte showed severe vascular degeneration in addition periportal fibrosis and coagulation of cutting area at 7 days( Figs 15,17) continued to 15 days associated with proliferation of fibroblast and collagen fiber between lobules, all these changes continued associated with fibrosis in portal area (Figs 18,19) Moreover, increase number of mitotic figures, hyperplasia of epithelial lining bile duct and fatty change in cytoplasm of hepatocyte in newly formed area (regenerate area) observed focal area of inflammation cells in hepatic tissue at 21 days. In addition to severe fibrosis in portal area, enlargement of hepatocytes and other, suffering from necrosis particularly (pyknosis).Moreover, at 21 days in areas fibrosis associated with increase number of mitotic figures, hyperplasia in epithelium lining bile duct associated with newly bile lacuni ,congestion, thrombus of blood vessels also observed.In group c, histological sections of hepatic tissues revealed normal architectures, consist from lobules each one consist from central vein surrounded by hepatocytes each together connected by 


\section{$\begin{array}{llll}\text { AL-Qadisiya Journal of Vet.Med.Sci. } & \text { Vol./12 } & \text { No./1 }\end{array}$}

sinusoid to consist hepatic cord, also lobules connected together by portal area (bile duct, portal artery, portal vein and lymphatics).

\section{Mitotic index}

Table 1 showed the percentage of mitotic figures in hepatocyte after 7,14and 21days post operation, which revealed increase percentage of mitotic index of hepatocyte in group A $30 \%, 33 \%$ and $15 \%$ respectively as compared to group $\mathrm{B}$ and $\mathrm{C}$ $(20 \%, 24 \%$ and $22 \%) ;(5 \%, 2 \%$ and $4 \%)$ respectively.

Table 1 Percentage of hepatic rate regeneration in rabbits with partial liver resection

\begin{tabular}{|l|l|l|l|}
\hline Groups & 7 days & 14 days & 21 days \\
\hline GA & 30 & 33 & 15 \\
\hline GB & 20 & 29 & 22 \\
\hline GC & 5 & 2 & 4 \\
\hline
\end{tabular}

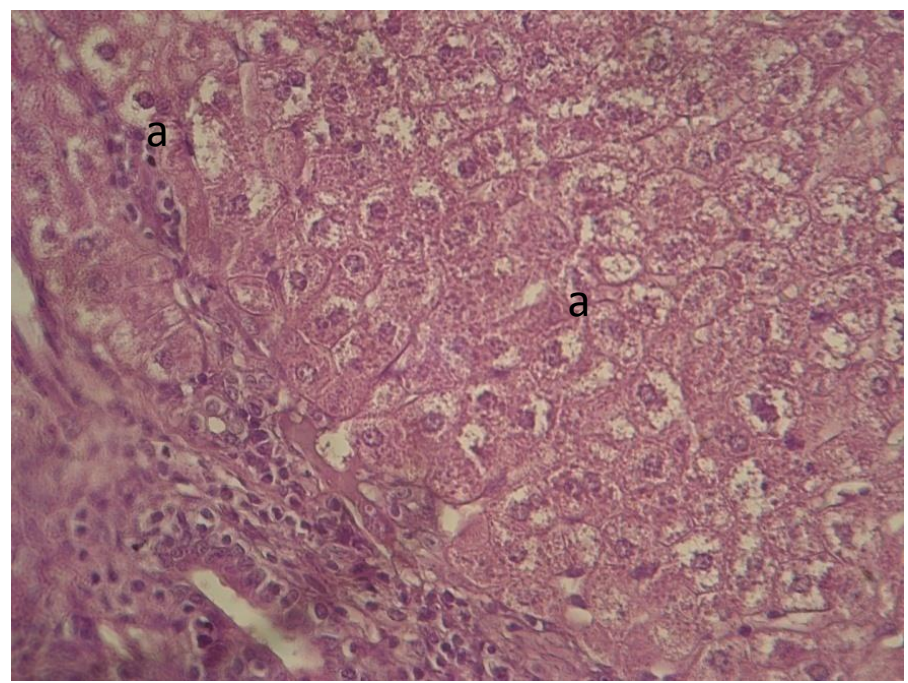

Fig. 5 Histopathological sections of rabbits" liver in group A at 7 days post operation showed vacuolar degeneration in hepatocyte(a) and mononuclear inflammatory cells infiltration in portal area .H\&E.

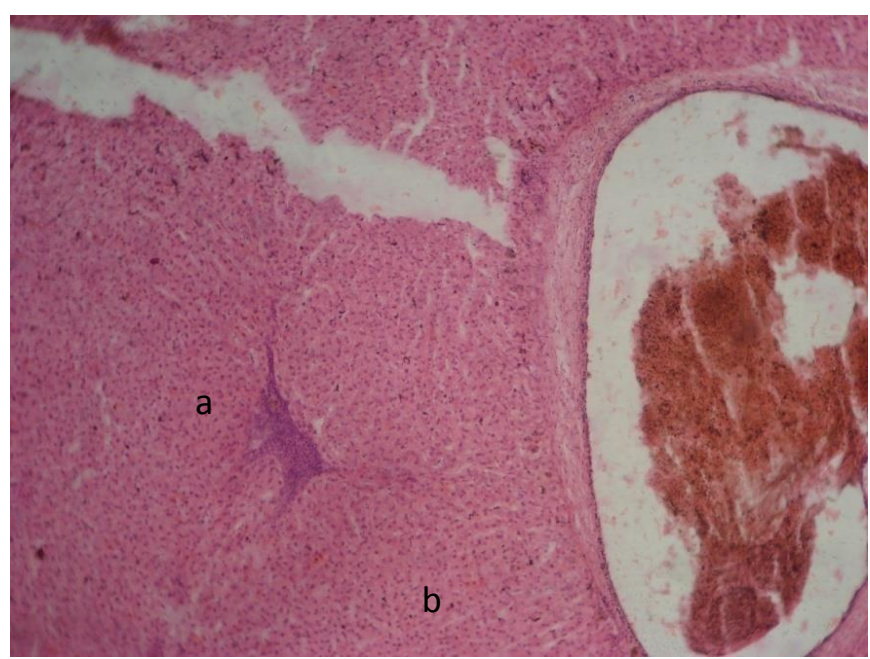

Fig. 6. Histological section of rabbits" liver in group A at 7 days post operation showed severe congestion of central vein (a) focal area of aggregation of mono nuclear inflammatory cells (b).H\&E. 


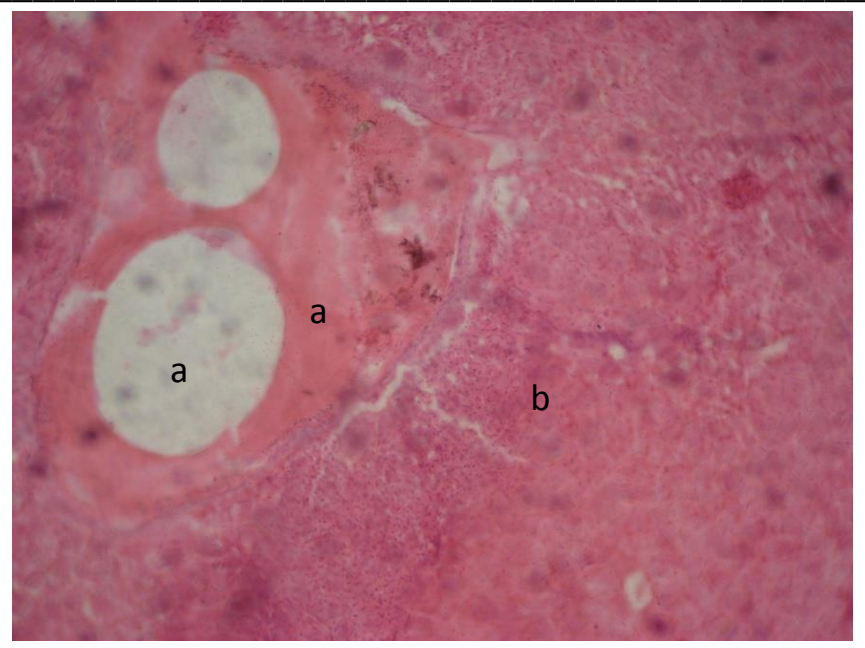

Fig. 7. Histopathogical section of rabbits' liver in group A at 7 days post operation showed dilation and thinking in the wall of blood vessels (a) deposition of bilirubin pigment (b).H\&E.

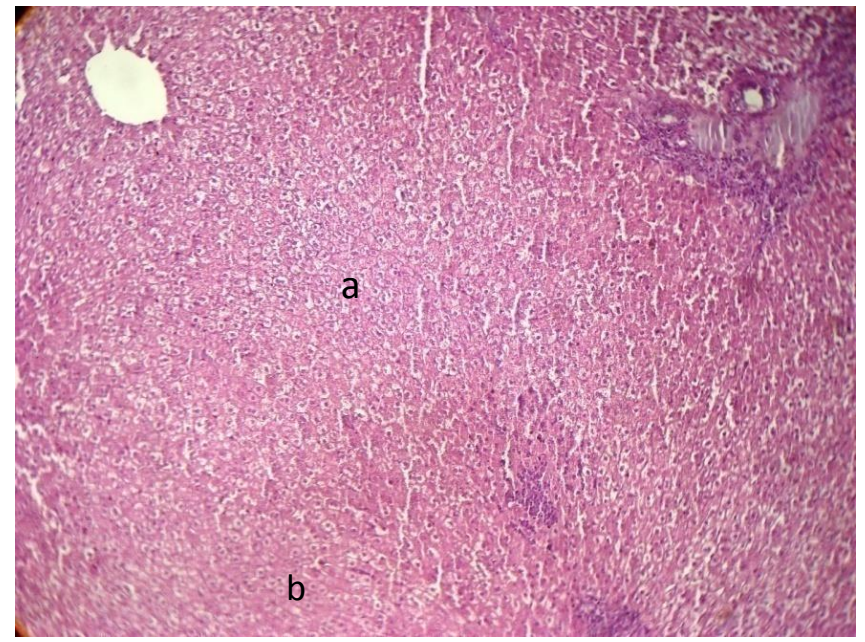

Fig. 8. histological section of rabbits' liver in group A at 15 days post operation showed portal fibrosis (a) and Island newly hepatocyte (b).H\&E.

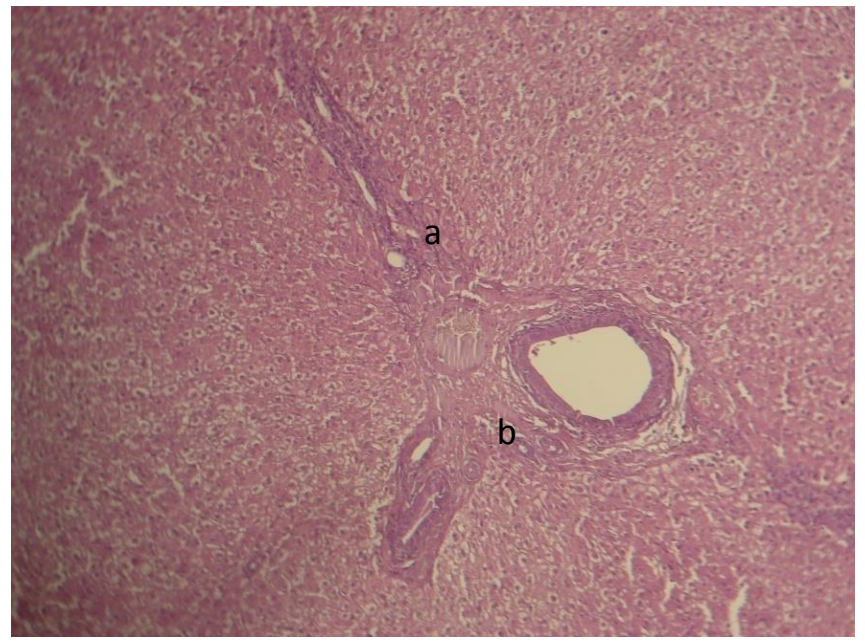

Figure 9. Histopathological section of rabbits' liver in group A at 15 days post operation showed fibrosis in portal area (a) and newly formed capillaries bile lacunae (b).H\&E. 


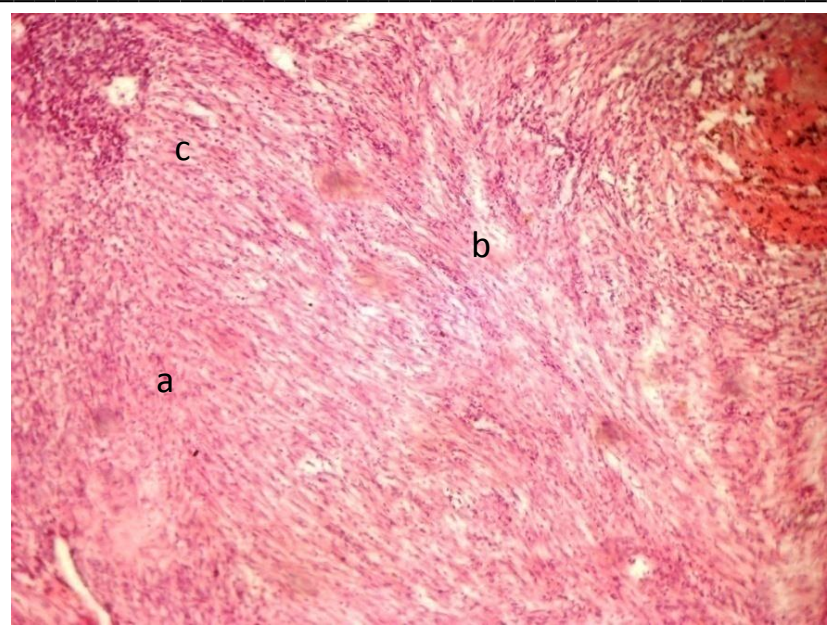

Fig. 10. Histopathological section of rabbits' liver in group A at 15 days post operation showed fibrosis (a) and newly formed capillaries (b)and Island of regenerated hepatocyte (c). H\&E.

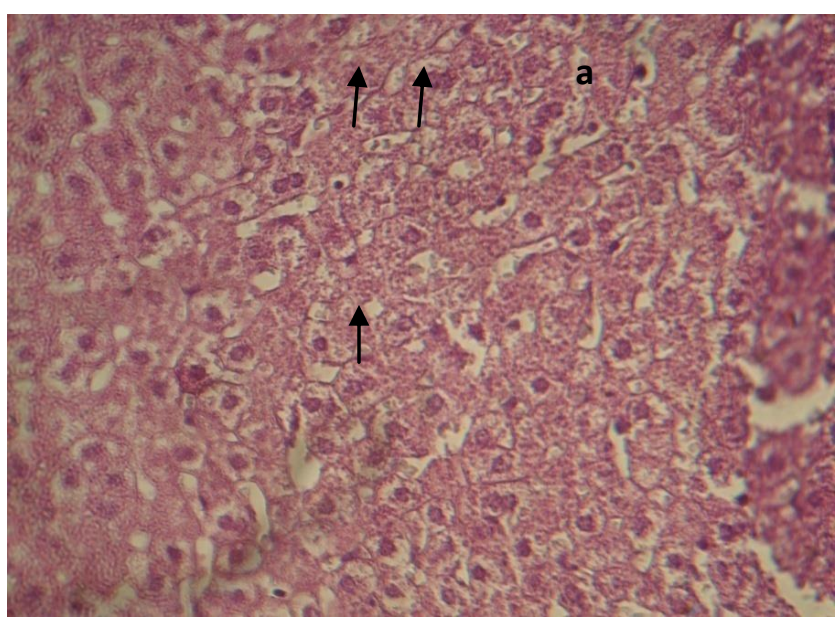

Fig. 11. Histopathological section of rabbits' liver in group A at 21 days post operation showed remnant area and regenerated area (a) vacuolar degeneration with granular cytoplasm (arrow).H\&E.

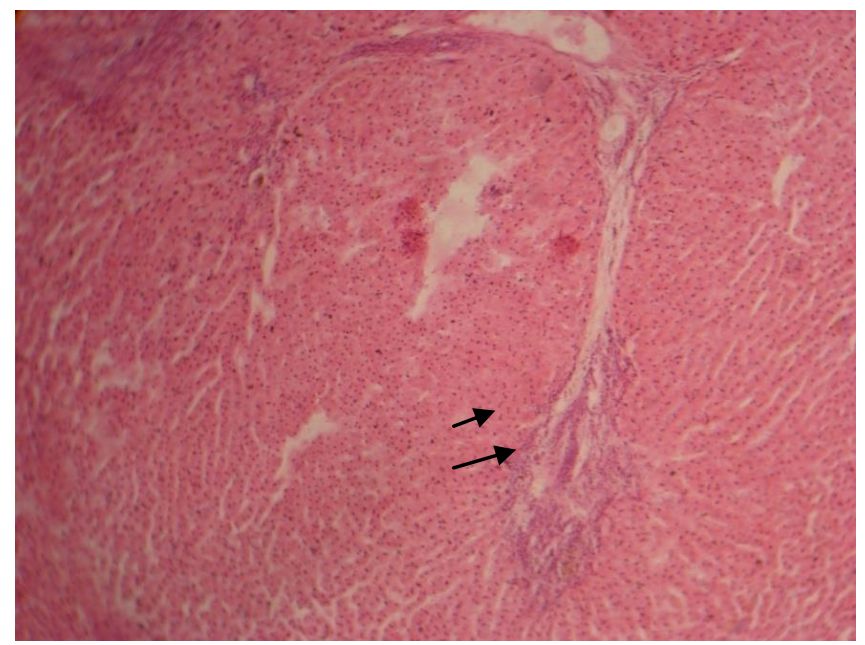

Fig. 12. Histopathological section of rabbits' liver in group A at 21 days post operation showed lobular and marinating with collagen fiber (arrows).H\&E. 


$\begin{array}{llll}\text { AL-Qadisiya Journal of Vet.Med.Sci. } \quad \text { Vol./12 } & \text { No./1 }\end{array}$

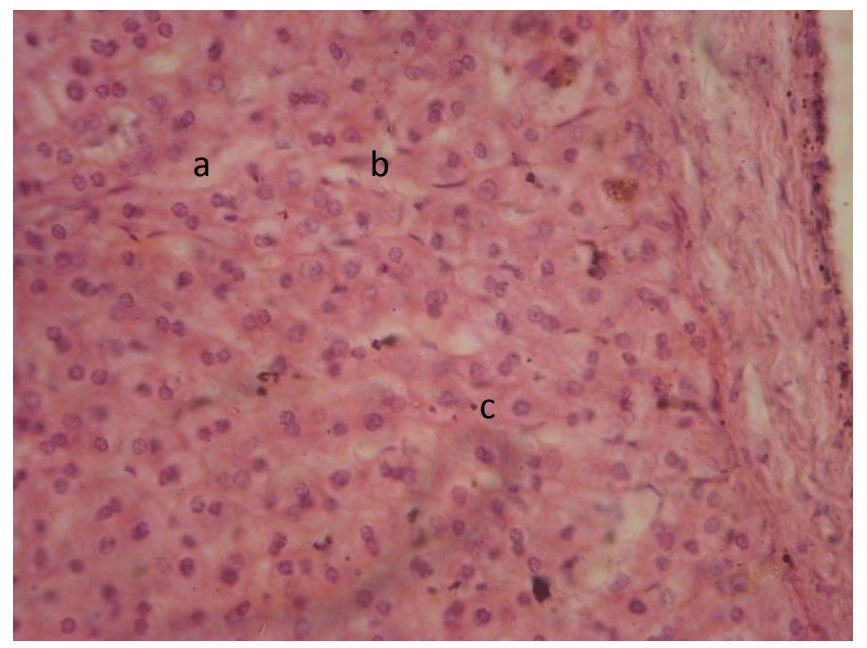

Fig.13. Histopathological sections of rabbits' liver in group A at 21 days post operation showed thickening in the wall o central vein (a) bilirubin pigment (b)and mitosis of hepatic nucleus (c).H\&E.

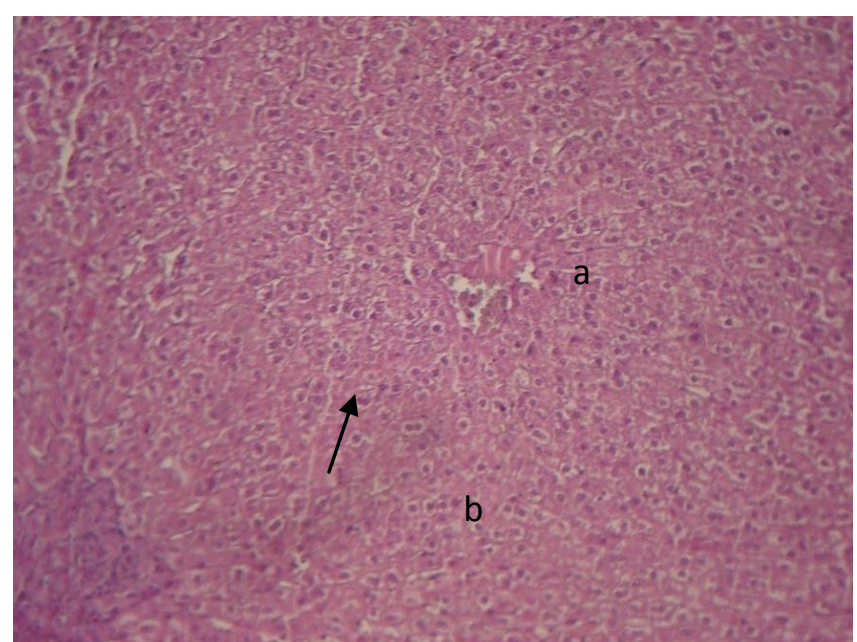

Fig. 14. Histopathological sections of rabbits' liver in group A at 21 days post operation showed apoptosis of hepatocyte (arrow) vascular degeneration (a)and mitosis figures (b).H\&E.

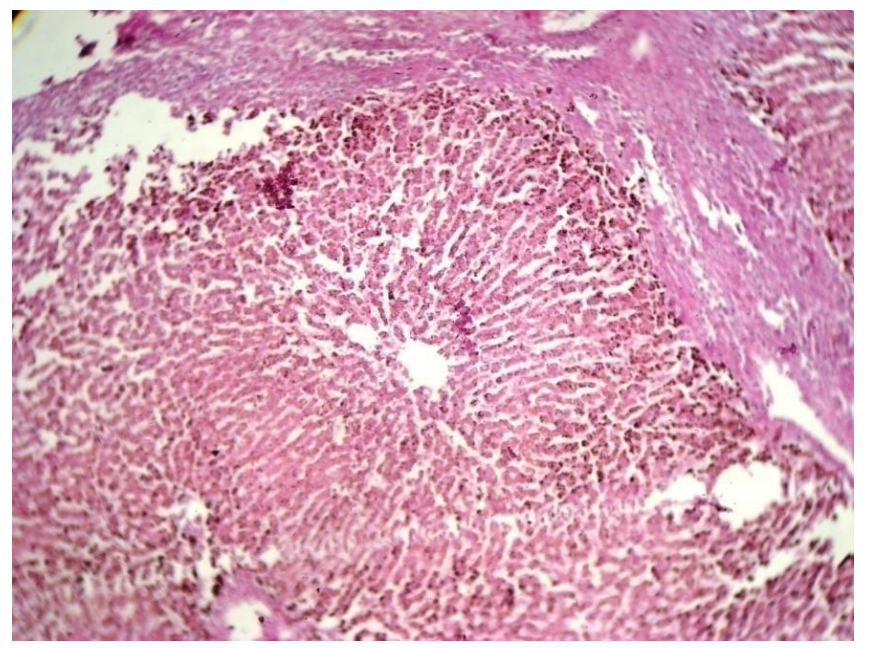

Fig. 15. Histopathology of rabbits' liver in group B at 7 days post operation showed perilobules fibrosis (a) hyperchromatic nuclei of hepatocyte (arrow) . H.E. 


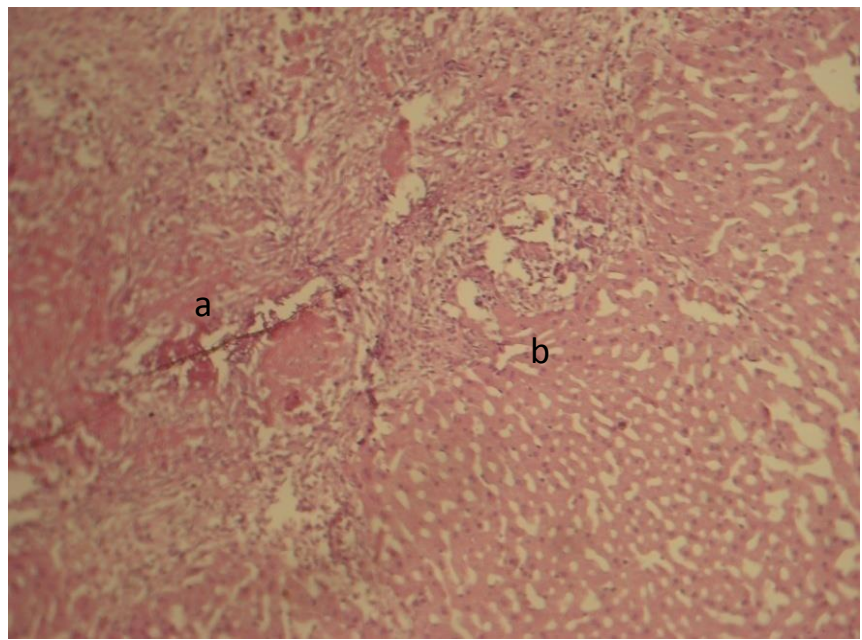

Fig. 16 Histopathological sections of rabbits' liver in group B at 7 days post showed coagulation at margins of cutting area (a), Dilation of sinusoids (b). H.E

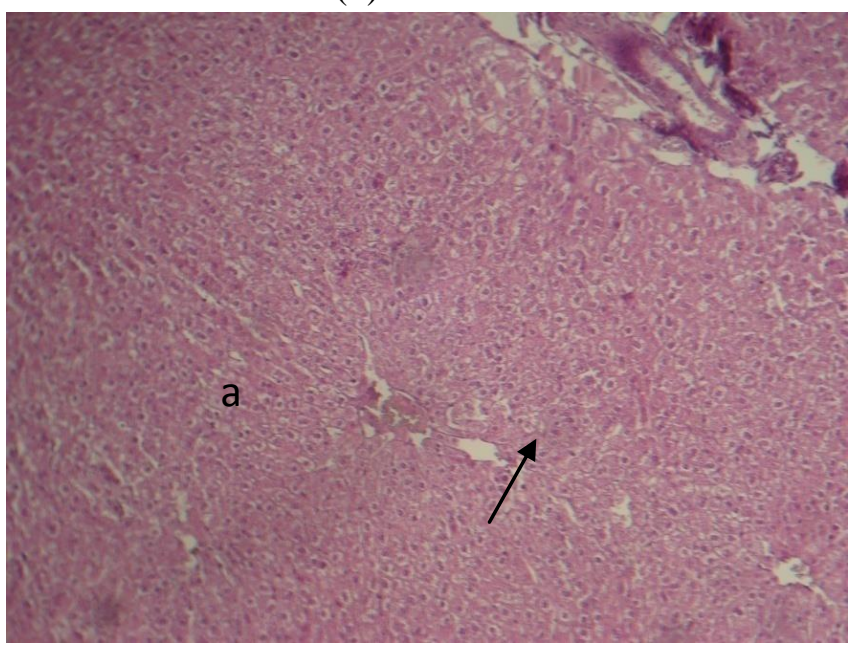

Fig.17. Histopathological sections of rabbits' liver in group B at 7 days post operation showed hyperplasia of bile duct (a) loss of hepatic cord arrangement (arrow) . H.E.

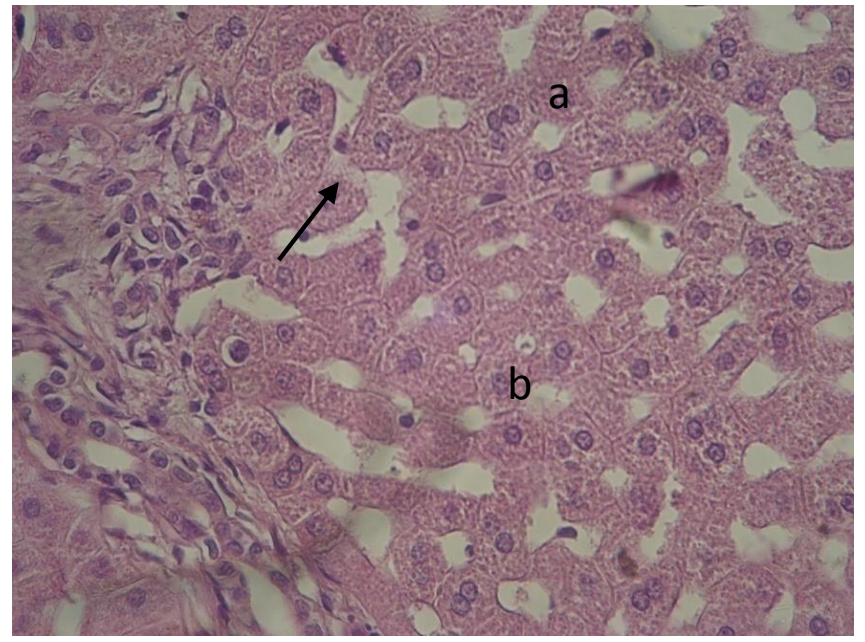

Fig. 18. Histopathological sections of rabbits ' liver in group B at 15 days post operation showed dilation in sinusoids (a) hyperchromatin nuclei of hepatocyte (b) and mitotic figures in portal area (arrow). H\&E. 


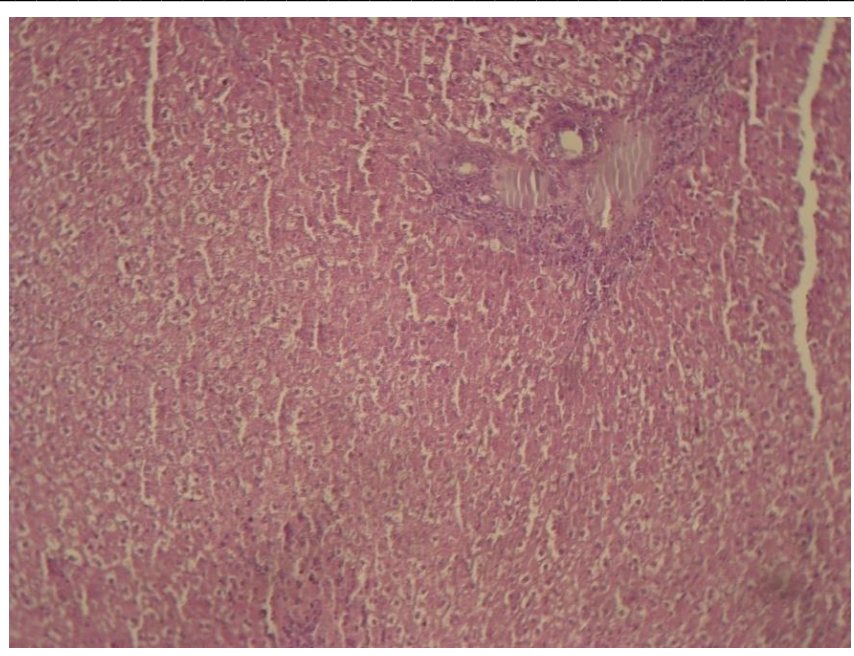

Figure 19. Histopathological sections of rabbits' liver in group B at 15 days post operation showed portal fibrosis (a) infiltration of mono nucleus inflammatory cells (b) . H.E.

\section{Discussion \\ Discusses}

Minimazing operative blood loss in liver surgery is important (11). The intraoperative control of bleeding involves techniques of both vascular occlusion and division of liver(11). Various techniques have been reported for division of liver, such as blunt dissection (12). The use of ultrasonic surgical aspirator (UCSA) or water-jet scalpel $(13,14)$, the microwave tissue coagulator method (15) and use harmonic scalpel $(11,16)$. The UCSA and ultrasonic surgical aspirator can divide the liver tissue by fracture aspiration of liver parenchyma but cannot be used for coagulation of tissue, unlike these instruments the heat gun for coagulation, thereby reducing time that needed to suturing liver parenchyma after cutting liver parenchyma. Une et al demonstrated cutting cirrhotic liver by using the water-jet scalpel in human's liver took much longer time than non cirrhotic liver parenchyma (17). Our technique using heat gun result in less time needed for control bleeding during dissection although we using normal liver but the same mechanism for control bleeding if diseased or normal liver. Thus we believe that our technique using hot air is a simpler method that does not depend as much on the operator's skill and experience as other techniques, and the procedure could also be performed in field for control liver bleeding due to trauma, thus we believe that our technique using the heat gun is a simpler method that does not depend as much on the operator's skill and experience as other techniques. No bleeding or bile leakage was observed following division of the shallow layer using a heat gun, and the procedure could also be performed in a field of less blood loss without vascular occlusion.It has been reported that the microwave tissue coagulator method can induce bile leakage or infection due to necrosis detachment of the cut margin of the residual liver (15). Indeed, there is no complications in association with the heat gun, such as postoperative bleeding, bile leakage, and abscess formation at the cut margins, were observed.In gross pathology in two groups the only gross pathology recorded the omental adhesion with stump, which is actually expected phenomenon. This omental adhesion was reported with partial splenectomy by use argon beam in rabbits (18) and partial splenectomy by suturing in rats(19) and laparoscopic partial splenectomy in $\operatorname{dogs}(20,21)$. In this study 
this type of adhesion could be considered as advantage more than disadvantage because the adhesion limited only the stump that made barrier for preventing likelihood additional with other neighboring viscera, furthermore preventing possible post operative bleeding.Many surgeons applying the omental flaps on the stumps during liver surgery to control bleeding post operatively $(22,23,24)$.Results histopathological study demonstrated that's partial hepatectomy by using heat gun give a good response for regeneration as compared with group B (extra corporeal suturing) via the percentage of mitotic figures which is higher in group A than in group B at a period 7-21 days (Table1),this results is in agreement with abdalla et al (25) Histopathological changes for remnant hepatic tissue revealed many changes indictor for initiated of regeneration in groups A and B but it more rapid in group A than in group B, this means that changes occur at 7days while in group B occurs at 14 days ,then results may be take place due to heat which in turn induce the metabolic activity of remnant hepatocytes to induce synthesis of DNA and other substances that are needed in regenerative activity, so cell swelling, fatty change (more in group A), congestion sinusoid . hypertrophy and hyperplasia of Kupffer's cell in addition fibrosis on portal area and newly formed capillaries with bile lacunae (26), all these changes occurs, as response to healing factors that are released from inflammatory cells and macrophage particularly (Kupffer's cells) for example hepatocytes growth factors which lead to rise cell cycle and transforming growth factors (TGFs), growth factor (GF) that originated outside liver to influence growth of regeneration hepatocytes during circulation in blood stream. Fibroplasia is also observed better in group A and particularly in portal area this also may be due to inducted to synthesis and release of collagen fiber type IV by hepatocyte, on the other hand, collagen for basement membrane is synthesized early with collagen type I and II which are produced later in hepatocyte injured after 21 days (27).In conclusion, while further studies on a greater number of human patients the use of many techniques for liver surgery, our techniques appears to be an effective device for liver surgery in rabbits model that minimizes blood loss and decreases the suturing time and regeneration of hepatic tissue by using heat gun more rapid then by extracorporeal suturing.

\section{References}

1. Hristov, H. ; Kostov, D.; Vladova D. (2007) topography anatomy of some abdominal organs in the rabbit.Trakia Journal of Sciences, 4 ( 3) :7-10.

2. Fossum,T.W.;Hedlund,C.S.;Johnson,A. L.;Schulz,K.S.;Seim,H.B.;Willard, M.D.;Bahr,

A.;Carroll,G.L.(2007).Small animal surgery .3rd Ed.Mosby Inc., China.pp.624-634.

3. Imamura H, Seyama $Y$, Kokudo $N$ et al.(2003) One thousand fifty-six hepatectomies without mortality in 8 years. Arch. Surg. 138:11981206.
4. Jarnagin WR, Gonen M, Fong $\mathrm{Y}$ et al (2002) Improvement in perioperative outcome after hepatic resection: analysis of 1,803 consecutive cases over the past decade. Ann. Surg. 236:397-406.

5. Kooby DA, Stockman J, Ben-Porat L et al.(2003) Influence of transfusions on perioperative and long-term outcome in patients following hepatic resection for colorectal metastases. Ann. Surg. 237:860869.

6. Lesurtel M., Selzner M., Petrowsky H. et al.(2005) .How should transection of the liver be performed?: a prospective 
$\begin{array}{llll}\text { AL-Qadisiya Journal of Vet.Med.Sci. } & \text { Vol./12 } & \text { No./1 }\end{array}$

randomized study in 100 consecutive patients: comparing four different transection strategies. Ann. Surg. 242:814-22.

7. Saiura A., Yamamoto J., Koga R. et al.(2006). Usefulness of LigaSure for liver resection: analysis by randomized clinical trial. Am. J. Surg. 192: 41-45.

8. Smyrniotis V., Arkadopoulos N., Kostopanagiotou G. et al.(2005) Sharp liver transection versus clamp crushing technique in liver resections: a prospective study. Surgery. 137:306-311.

9. Takayama T., Makuuchi M., Kubota K. et al.(2001). Randomized comparison of ultrasonic vs clamp transection of the liver. Arch. Surg. 136:922-928.

10. Cavas, T. and S. Ergene Gozukara (2003):Micro-nuclei,nuclear lesions and interphase silver-stained nucleolar organizer regions (AG NOBS) as cytogenotoxicity indicators in oreochromis niloticus exposed to textile mill effluetmutat. Res.; 538 (1-2): 81-91.

11. Sugo, H. ; Mikami Y. ; Matsumoto, F.; Tsumura, H.; Watanabe Y.; Kojima, K.; Futagawa, SH. (2000). Hepatic resection using the harmonic scalpel Surg .Today . 30:959-962.

12. Makuuchi M., Hasegawa H., Yamazaki S. (1985).Ultrasonically guided subsegmentecto-my. Surg. Gynecol. Obstet. 161:364-370.

13. Tranberg K.G., Rigotti P., Brackett K.A., Bjornson H.S., Fischer J.E.,Joffe S.N. (1986). Liver resection. A comparison using the Nd-YAG laser, an ultrasonic surgical aspirator, or blunt dissection.Am J Surg 151:368-373.

14. Amaral J.F. (1994). The experimental development of an ultrasonic activated scalpel for laparoscopic use. Surg. Laparosc. Endosc. 4:9299.

15. Lau W.Y., Arnold M., Guo S.K., Li A.K. (1992). Microwave tissue coagulator in liver resection for cirrhotic patients. Aust. N .Z. J. Surg. 62:576-581.

16. Trupka A., Hallfeldt K., Kalteis T., Schmidbauer S., Schweiverer L.(1998). Open and laparoscopic liver resection with a new ultrasoundscalpel (in German with English abstract). Chirurg.69:13521356.

17. Une Y., Uchino J., Horie T., Sato Y., Ogasawara K., Kakita A., Sano F.(1989). Liver resection using a water jet. Cancer Chemother. Pharmacol. 23:S74-S77.

18. Stylianos, S.; Hoffman, M.A.; Jacir, N.N.; Harris, B.H.(1991).Sutureless hemisplenectomy. J. Pediatr. Surg. 26(1):87-89.

19. Paulo, D.N.; Paulo, I.C.; Kalil, M.; Vargas, P.M.; Silva, A.L.; Baptista, J.F.; Guerra, A.J. (2006).Subtotal splenectomy preserving the lower pole in rats: technical, morphological and functional aspects. Acta Cir. Bras. 21: 321327.

20. Al-Heani W.,2008. Laparoscopic partial splenectomy in dogs. M.Sc. Thesis, College of Veterinary Medicine, University of Mosul, Mosul, Iraq.

21. Al-Hasan A. and Al-Heani W.,2009. Laparoscopic partial splenectomy in dogs. Journal of Animal and Veterinary Advances.8:2232-2240.

22. Hoekstra, H. J. ;Tamminga, R.Y.;Timens, W. (1994). Partial splenectomy in children: an alternative for splenectomy in the pathological staging of Hodgkin's disease. Annals of Surgical Oncology, 1(6):480-486. 
$\begin{array}{llll}\text { AL-Qadisiya Journal of Vet.Med.Sci. } & \text { Vol./12 } & \text { No./1 }\end{array}$

23. Hery, G.; Becmeur, F.; Me'fat, .; Kalfa, D.; Lutz, P.; Lutz, L.; Guys, J.; Lagausie, P. (2008). Laparoscopic Partial Splenectomy: Indications and results of a multicenter retrospective study. Surg. Endosc. 22:45-49.

24. Greef, E.D.; Hoffman, I. ;Topal, B.; Broers, C.; Miserez, M.(2008). Partial laparoscopic splenectomy for splenic abscess because of Salmonella infection: a case report. J. Pediat. Surg.43: E35-E38.

25. Abdalla, O. A., Awad ,M. A., Helmy ,S.

A., and Abdou ,M.T.. (2009).
Histological and clinicopathological studies following partial hepatectomy in dogs. J. Vet. Anat. Vol .2 No.1, (2009) 17 - 34.

26. Starzel, T. E.;A. Francavilla and C. G. Halgrimson (1987).The origin, hormonal nature and action of hepato-tropic substances in portal vein blood surgical. Gynecol. Obstet., 137: 179-199.

27. Vacca, L. L. (1985). Laboratory mannual of histochemistry. Roven Press, New York. P186-189.

\section{الاز الة الجزئية للكبد باستخدام اداة جديدة في نموذج الارانب}

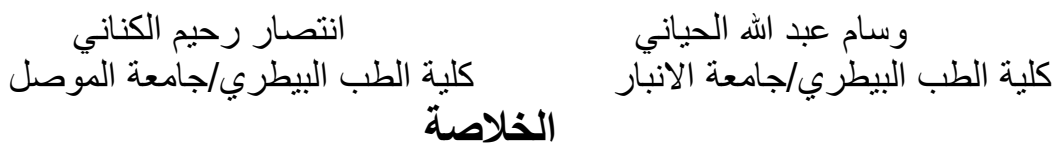

هدفت الدراسة إلى تقييم كفاءة أداة جديدة (المدفع الحراري) في جر احة الكبد.ولأول مرة تم استخدام الأداة في الجراحة

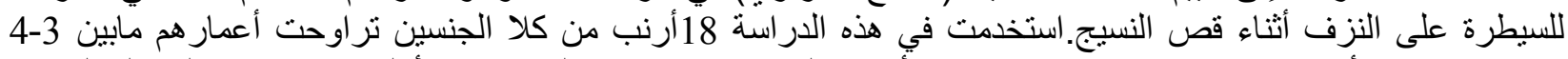

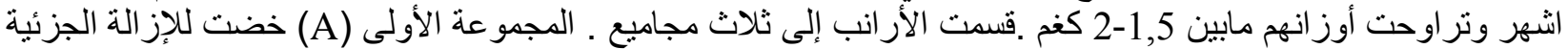

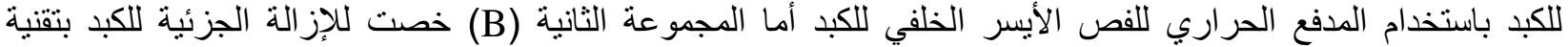

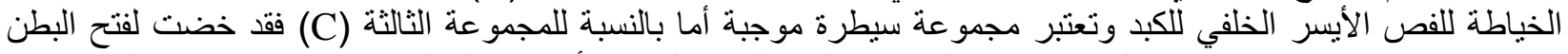

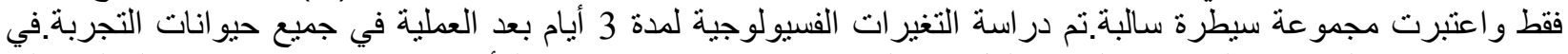

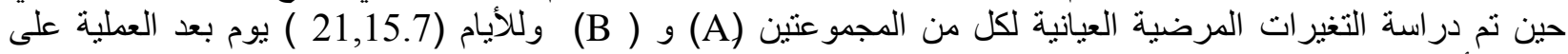

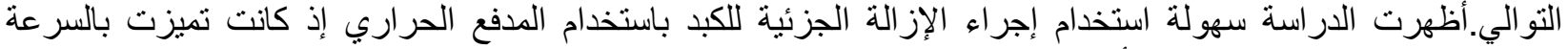

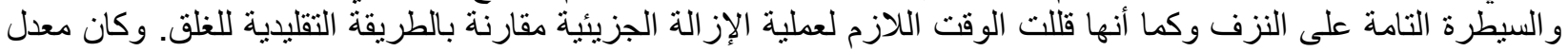

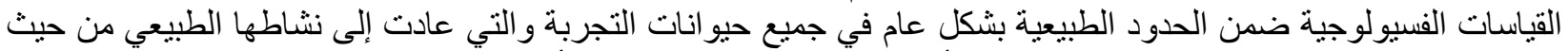

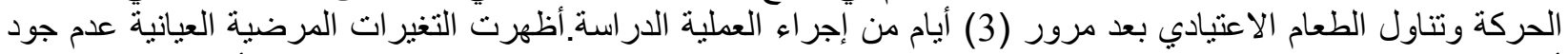

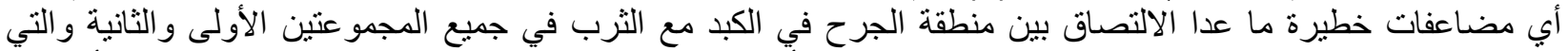

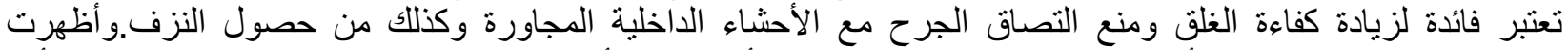

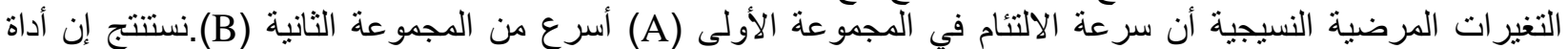

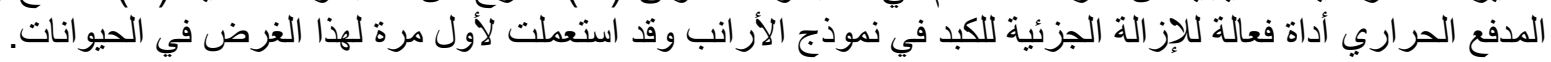

